\title{
Teacher Participation In Stress Management Through Different Theoretical Lenses: A Study Conducted In The Mahikeng Area
}

A.M.F. Pelser, North-West University, South Africa

C. van Wyk, North-West University, South Africa

\begin{abstract}
The purpose of the research reported in this article was to place the known facts of the topic of teacher participation in stress management in the context of management and leadership in education. The emphasis in the conceptual and theoretical framework was on showing points of connection between leadership and management on the one hand and stress on the other. The investigation focused on how theoretical points of departure impact on teachers and how teachers experience stress through participation or non-participation in school management. The theoretical investigation was followed by a quantitative investigation by using a structured questionnaire known as the ASSET tool (An Organisational Stress Screening Tool) developed by Carthwright and Cooper. The main objective of the questionnaire was to measure potential exposure to stress in respect of common workplace stressors. The instrument was used to conduct a survey amongst teachers in the Mahikeng area. It was found that although there are many examples of how aspects of the different theories can be applied in the practice of stress management, the reality is that managerial leadership still features strongly in schools and that, in many instances, transformational and distributed leadership does not provide realistic alternatives to stress management theories in schools.
\end{abstract}

Keywords: School-Based Management (SBM); Educational Management; Educational Leadership; Stress Management; Stress Leadership; Transformational Leadership; Shared Leadership; Managerial Leadership; Distributed Leadership

\section{INTRODUCTION}

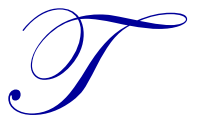
he decentralisation of authority has been a critical issue in the South African education system in the past 20 years. Subsequent to the advent of the new democratic system and the promulgation of the South African Schools Act ([SASA], RSA, 1996), various South African authors explained and deliberated on the introduction, implementation and effect of decentralisation in education through the system called School-Based Management (SBM). The application and implementation of SBM through its different features - such as the functioning of School Governing Bodies, school leadership, financial school management, the role of parents in school governance, school development planning, management through teamwork, management of teaching and learning, the nature of the relationship between leadership and organisational culture, continuing professional development and school effectiveness - were highlighted in various ways (Mncube, 2009; Singh \& Lokotsch, 2005; Prew, 2007; Van Niekerk \& Van Niekerk, 2006; Van der Mescht \& Tyala, 2008; Heystek, 2007; Heystek, 2011; Moloi, 2007; Niemann \& Kotzé, 2006; Christie, 2010; Botha, 2011; Steyn, 2011).

Teacher participation in school management has been well researched from different perspectives. Obviously, the ideal is that leadership should be dispersed throughout the school and management activities should be delegated to stakeholders such as teachers (Christie, 2011). Wadesango (2011) found that there are many advantages of teacher participation in decision-making and Mokoena (2012) indicated that participative management affects the trust level in schools. It has also been stressed that teacher participation in school management is of critical importance, particularly when it is linked to the effects that teachers' participation might have on school outcomes (Somech, 
2010). Teacher participation in school governance, for the sake of improving decision-making in teaching and learning, thus seems vital (Van Wyk, 2004).

There are many detailed accounts of work-related stressors in South African schools. Issues such as new curricula, teacher shortages, increasing changes in education and society, and teachers that are burdened with having to make a variety of modifications in their personal and professional lives, as well as inadequate or irrelevant educator training programmes, have been related at length. Researchers such as Schulze and Steyn (2007) also conducted projects and published reports on current stressors in the professional lives of South African secondary school educators, the burnout and engagement of teachers (Jackson, 2004), burnout of secondary school teachers in the Goldfield region of the Free State Province (Van Wyk, 2004), as well as the causes of stress of educators in public schools in Kwazulu-Natal and how it impacts on work performance (Naidoo, 2011).

Although the relations between teacher participation and the different sides of SBM, as well as the connection of these to stress-related matters, can be indicated in a linear way, managerial and leadership issues have the potential to complicate matters. It seems that the stress that teachers experience in schools can, in many instances, be connected to challenges concerning the implementation of different leadership theories and practises. Teachers' own involvement in stress management is another key facet that was investigated.

\section{PROBLEM STATEMENT AND RESEARCH QUESTIONS}

Very few, if any, studies have attempted to investigate the relationship between stress management, teacher participation and leadership theories. Most investigations focus on the reasons for the stress experienced by teachers but not on what leaders, including teachers themselves, can do to manage or cope with such stress.

The purpose of this article was to determine what the perceptions of teachers were on their participation in stress management through different theoretical lenses. In this process, the aims were to establish what the conceptual differences between the terms management and leadership entail and to indicate which theories can be applied to the management of stress in schools.

\section{CONCEPTUAL AND THEORETICAL FRAMEWORK}

\section{The Concepts Management and Leadership}

Many authors in the field of educational management and leadership explain that it is of critical importance to distinguish between the concepts management and leadership (see, for example, Bush, 2007; Marishane \& Botha, 2011; Christie, 2011). Management is usually seen as a "maintenance" kind of activity, with the emphasis on the "internal operations" of an institution, in terms of which managing the organisational affairs efficiently and effectively receive preference (Bush, 2007). This means that "management involves dealing with systems, structures and the culture of a school for effective and smooth day-to-day operations" (Naidu et al., 2011). On the other hand, leadership is linked with change and with "influencing others" to achieve desirable future-oriented ends (Bush, 2007). Traditionally, leaders were seen as people who shape the goals, motivations and actions of others. They initiate change to reach existing and new goals. The concept management is more likely to be tied to formal positions than to persons, whereas leadership is characterised by influence and consent rather than coercion (Christie, 2011).

Other authors in the field indicate that although the two terms are distinguishable, they should be applied in practice in an integrative way. It is recognised that educational leadership and educational management are two sides of the same coin and should not be seen as separate, loose-standing concepts with different meanings that are based on dissimilar theories. Instead, Christie (2011) argues that "ideally, schools should be replete with good leadership, at all levels; they should be well managed in unobtrusive ways; and principals should integrate the functions of leadership and management and possess skills in both". This kind of thinking is in line with Bush (2007) who observes that "the concepts of management and leadership overlap each other" and also with Fink (2011), quoting Gronn (2009), who found that there are very few differences between the two terms and who in fact reckons that the term management "was given a linguistic makeover and became leadership". The researchers thus applied these two 
crucial terms in a synonymous way, without attempting to focus on technical and linguistic distinctions, but recognition is given to the fact that although the bulk of the investigation is located within what is generally called "the field of Educational Leadership", the term used in literature is stress management and not stress leadership (Schulze \& Steyn, 2007).

\section{Theories In Educational Management And Leadership}

Considerable theorising has been conducted in the field of Educational Management in the last decade (see, for example, Bush, 2007; Crawford, 2012; Christie, 2010; Leithwood \& Sun, 2012). The existence of several different perspectives creates what Bolman and Deal (1997) describe as "conceptual pluralism: a jangling discord of multiple voices". These perspectives obviously relate to a changing situation and comprise different ways of seeing a problem. Each theory has something to offer in explaining behaviour and events in educational institutions. The perspectives are adopted explicitly or implicitly by different researchers, but inevitably influence and even determine the ways in which they think and write about educational management issues. It is important to note, in this regard, Morgan's (1997) observation that "any theory or perspective that we bring to the study of organisation and management, while capable of creating valuable insights, is also incomplete, biased and potentially misleading". What makes it even more problematic to get a comprehensive view on theories is that as time went by, some of the most influential academics in the field apparently acquired new insights and adjusted or extended their original thinking to include a whole new range of ideas. Bush's first book, Theories of Educational Management, for example, was originally published in 1986 and discussed five theories or models; namely, formal, democratic, political, subjective and ambiguous (Bush, 1986). By 2007, he added collegial and cultural models and omitted democratic models from his management models. He also added and discussed nine so-called leadership models, however - managerial, participative, transformational, interpersonal, transactional, post-modern, contingent, moral, and instructional (Bush, 2007). Another example of researchers, who at first identified certain theories and later came to a different view, are Bass and Avolio (1991 \& 1993) who later on combined their initial nine factors which described leadership styles into three - the transformational, the transactional, and the avoiding or passive style (Mannheim \& Halamish, 2008).

The development of thought and theories in the field of educational management has further been well documented in different sources such as The Sage Handbook of Educational Leadership (English, 2005) and prestigious research journals like Educational Management Administration \& Leadership and Educational Administration Quarterly. The development of theories from scientific management, with its technical-rational perspective and emphasis on organisational goals and formal structures, is explained in detail in these publications (cf. Dantley, 2005; Ogawa, 2005). It was recognised that in the late 1980s, though, there was a move towards theories that involve leadership in all its forms (Crawford, 2012).

Leithwood and Sun (2012) indicate that there has been a change from traditional transactional models of leadership to those that are transformational in nature. Caldwell and Spinks (2006) see this change as two-dimensional; namely, concern for accomplishing the tasks of the organisation and concern for relationships among the members of the organisation. Some writers clustered various conceptions into a number of broad themes or "types", while others attempted to formulate "new" theories. Crawford (2012), for example, concluded that "shared leadership, variously described as democratic leadership, collegiality, participative leadership and distributed leadership, have replaced solo leadership in education organisations".

Dambe and Moorad (2008) explain that in 1978, Burns triggered the shift in thinking from authoritarian leaders to those who were willing to share power. This is described as a paradigm shift from power-based leadership theories to an empowerment approach (Dambe \& Moorad, 2008). So, with the risk of simplifying complicated issues, it seems as if the initial emphasis that was placed on traditional scientific theories has been complemented with transformational theories and that it has taken another turn away from transformational leadership, towards participative or distributed leadership (Hartley, 2010). This means that theory on leadership has undergone a major paradigm shift from the traditional view of leadership as centred on the role of individual leaders to alternative theories which place the focus on multiple participants. The weight of the leadership argument has been re-located from an over-reliance on the leader's influence to determining relevant variants of leader influence (Williams, 2011). 
In summary, the three main strands of leadership and management theories in the field of education management are centred on managerial, transformational and distributed perspectives. In the rest of this article, these explications will be used for the purpose of creating a basis for the empirical study. It is important to note that the different perspectives are not mutually exclusive, as if only particular theories or insights relate to a certain time or context. Theories or models are timeless and will always apply to a greater or lesser extent in different settings. This reality was applied in the following discussion and based on the fact that one would inevitably find features of a whole range of theories present in any practical educational situation.

\section{Theories Applied in Practice}

\section{Managerial Leadership}

Most approaches to managerial leadership assume that the behaviour of organisational members is largely rational and that decision-making is centralised: "Authority and influence, are allocated to formal positions, in proportion to the status of those positions in the organisational hierarchy" (Leithwood et al., 1999). According to this paradigm, leaders are associated with commanding, controlling, being authoritarian and showing an unwillingness to share power (Dambe \& Moorad, 2008). Caldwell (1992), as quoted in Bush (2008), identified seven steps that form part of managerial functions; namely, goal-setting, needs identification, priority-setting, planning, budgeting, implementing, and evaluating. The traditional POLC management functions can also be seen as steps in Table 1 .

\begin{tabular}{|c|c|}
\hline Planning & Organising \\
\hline $\begin{array}{l}\text { Aims } \\
\text { Objectives } \\
\text { Policy-making } \\
\text { Decision-making } \\
\text { Problem-solving }\end{array}$ & $\begin{array}{l}\text { Creating organisational structure } \\
\text { Delegating } \\
\text { Coordinating }\end{array}$ \\
\hline Guiding/Leading & Control \\
\hline $\begin{array}{l}\text { Building relations } \\
\text { Leadership/Guiding } \\
\text { Motivating } \\
\text { Communication }\end{array}$ & $\begin{array}{l}\text { Controlling instructions } \\
\text { Observing and measuring } \\
\text { Evaluating } \\
\text { Corrective action }\end{array}$ \\
\hline
\end{tabular}

(Van der Vyver, 2012)

When the above-mentioned aspects are applied to a school, a closed communication system results with a rigid leadership style, where the lines of authority from principal to deputy head and then to heads of departments are clearly defined, with the principal being regarded as occupying the most central position in the school (Naidu et al., 2011). Teachers are usually not involved in any form of management. Naidoo (2011) admits that the abovementioned kind of structural arrangements have certain advantages and that "this kind of leadership is suitable to deal with matters that are routine and predictable and particularly appropriate when staff consists of new or inexperienced, and even under-qualified, educators". Bush (2007) points out that "achieving functional schools is an essential requirement if learning is to take place and therefore managerial leadership remains important for 21 st century South Africa". It must also be kept in mind that in the South African system, it is widely reported that under "apartheid, educational administration was characterised by a high degree of centralisation and was operated along bureaucratic administrative lines" (Christie, 2010). Therefore, it is only realistic to expect that some of the key characteristics of the previous system will still be in operation, to a greater or lesser extent, throughout the current system. Formal chains of command are firmly entrenched through the hierarchical structure and heads of department and principals are officially responsible for managing staff matters such as workload, staff development and any other management issues, like conflict and stress. Apart from having to manage stressful issues and situations, staff in leadership positions also have to manage the consequences of stress that stem from personal relationships. Principals could apply a range of stress management techniques linked to POLC. Some or other combination of good and effective communication, planning, leadership, organising and strict control could be useful in this regard. 


\section{Transformational Leadership}

Unlike managerial leadership, where the focus is specifically on direct coordination, control, and supervision, transformational leadership has to do with motivating followers to action by appealing to shared values and by inspiring them to become highly engaged and motivated by goals that are inspirational because those goals are associated with values in which they strongly believe or are persuaded to strongly believe (Leithwood \& Sun, 2012). A transformational leader is a futurist who creates a compelling vision that inspires total commitment to, and acceptance of, change by followers. In this thinking, emphasis is put on the leader and management team who lead change and who empower those who participate in the process (Singh \& Lokotch, 2005).

The key element of transformational leadership is making and implementing changes concerning values, beliefs and organisational goals. Transformational leadership theory claims that a relatively small number of leadership behaviours or practices are capable of increasing the commitment and active participation of other organisational members, such as teachers, toward the achievement of objectives. Clearly, teachers have to give adequate support to ensure successful implementation of these key matters.

The quality of transformation will ultimately not only depend on the nature and quality of the leadership but also on the degree to which ordinary teachers share the vision of the leaders. Changes have to be introduced in such a way that they are effective and can contribute to managing the causes of stress amongst teachers in the school. Motivation and inspiration can also be best achieved in an environment where stress is managed continuously and efficiently.

To ensure the efficiency of stress management, attention has to be paid to the critical transformational leadership issues, such as the eight dimensions of building a vision, establishing school goals, providing intellectual stimulation, offering individualised support, modelling best practices and important organisational values, demonstrating high performance expectations, creating a productive school culture and developing structures to foster participation in school decisions (Leithwood, 1994, as quoted by Bush, 2007).

Another example of a model for the development of transformational leadership skills that has already been implemented in the educational sector was developed by Gill (2003) who included in his model the aspects of vision, values and culture, strategy, empowerment, and motivation and inspiration.

In the South African context, the "concept transformation has a special meaning linked to the need to convert the previous stratified system into a new framework stressing equity and redress" (Bush, 2007). Davies (2012), who wrote from a financial management perspective, also identified access as one of the norms that should be achieved in the new system. The term equity has to do with the development of policies that "would seek to ensure that the outcomes of public schooling are just and fair for each of its clients" (Davies, 2012). Obviously, equity does not mean "sameness" since learner input-costs cannot "be identical because the reality is that some learners require more by way of input costs to arrive at an output comparable with that of others" (Davies, 2012). The term access clearly involves admission to schools, but Davies (2011) explains that although everyone has the right to basic education, it is not free of charge. Parents are required to pay a user charge known as school fees. Even though some parents are either not required to pay or are exempted from paying this user charge, the main question still remains how quality can be advanced throughout the system in the absence of a user charge. Redress "can be taken to mean putting right that which is wrong or in some way compensating for past injustices" (Davies, 2012). This aspect obviously deals with a wide range of issues that affect the professional lives of teachers. The climate and culture in which they function on a daily basis is such an example.

\section{Distributed Leadership}

The central premise of distributed leadership is that all the management activities and processes are spread throughout the organisation. Williams (2011) reports that there has been a movement away from an over-reliance on the leader's influence, to determining relevant variants of leader influence, to arguing for distributive leadership. According to Harris (2004), the main advantage of this way of doing is that expertise is engaged "wherever it exists within the organisation rather than seeking this only through the formal role". It is also important to note that with 
true distributed leadership, stakeholders, such as teachers, are actually involved in decision-making and not just representatives or so-called co-opted members (Somech, 2010). Building on the ideas of distributed cognition, distributed leadership describes the ways that leadership activities are stretched across different people and positions within organisations and where the result is greater than the sum of the individual parts (Flessa, 2009). The main advantage of distributed leadership is the direct involvement of parties and not just their representation. Representatives are thus not just there to provide advice, but they have the right to make or heavily influence final decisions (Somech, 2010). Teacher participation, in particular, can enhance a sense of fairness and trust in the school because they can defend their own interests and get information on the shaping of decisions to which they would not otherwise be privy.

What is of particular importance in the case of schools and teachers is that a key element of distributed leadership is instructional leadership. Wadesango (2011) explains, in this regard, that teachers are the direct custodians of the curriculum implementation process and that it is therefore the correct place where their expertise must be used. In larger schools, it is especially clear that the principal cannot be the only person involved in monitoring and developing the school's instructional programme. Teachers understand instructional-related issues and work processes better than administrators or policy-makers; their participation ensures that better information will be available for making decisions to facilitate improved performance. Williams (2011) confirms that distributed leadership is the form of leadership most closely associated with improved learning outcomes and school improvement is the obvious vehicle to increase learner performance. In this way, an internal network of teacher-led teams, performing specific tasks but interacting with one another to achieve the common goal, can be set up (Marishane \& Botha, 2012).

\section{EMPIRICAL STUDY}

\section{Research Design}

A cross-sectional survey design, with the focus on relationships between and among variables in a single group, was used. Data were collected by means of a structured questionnaire known as the ASSET (An Organisational Stress Screening Tool) that was developed by Cartwright and Cooper (2002) as an initial screening tool to help organisations assess the risk of occupational stress in their workforce. The main objective of this questionnaire is to measure potential exposure to stress in respect of common workplace stressors.

Jackson (2004), Jackson and Rothman (2006) and Naidoo and Botha (2012) successfully applied the ASSET as a valid measuring instrument in the Free State, North West and KwaZulu-Natal provinces of South Africa, showing that the reliability of the data and validity of the instrument are satisfactory for the South African educational environment.

\section{Study Population and Sampling}

This study was conducted in the Mahikeng area of the North West Province of South Africa which is an area that is unique in many ways. In the previous political dispensation, it formed part of the Bophuthatswana homeland. During that time, a strong infrastructure for government was established in the towns consisting of Mahikeng and Mmabatho. After 1994, Mahikeng was entrenched as the capital city of the province and included a wide range of geographical areas from adjacent regions. The city itself is unique in the sense that, apart from government, a large number of related industries and businesses were established, mainly by black entrepreneurs.

The schools in and around Mahikeng that are the object of this investigation could be seen as schools for a wellestablished and growing middle and upper class of mainly black people. As such, the investigation deals with teachers who are working in a unique environment with its own set of demands and challenges. A total of 955 educators are employed in the secondary schools in the Ngaka Modiri Molema District of the Mahikeng education region.

The Ngaka Modiri Molema district is divided into five clusters and all the educators from secondary schools from the clusters were approached to complete the questionnaire. Schools were visited and a total of 955 questionnaires 
were provided to school principals for distribution to educators. A total of 372 questionnaires were collected after one week. Only a total of seven were rejected due to non-completion, leaving a total of 365 completed questionnaires being submitted for statistical analysis. This total represents $38 \%$ of the sample.

\section{Statistical Description}

The study employed the statistical software programme SPSS 17.0 (SPSS Inc., 2009) for Windows to analyse the data. The statistical techniques, which embody a sound statistical procedure, its application settings and interpretation in this study, are introduced below.

- Kaiser-Meyer-Olkin (KMO) measure of sampling adequacy

- Bartlett's test of sphericity

- Exploratory factor analysis

- Cronbach Alpha's reliability coefficient

- Pearson's correlation coefficient

The KMO is employed primarily to ensure that the data are suitable for multivariate statistical analyses because factor analysis was the primary statistical analysis tool in this research. A minimum KMO value of 0.7 was set for this study, as advised by the NWU's Statistical Consultation Services (Ellis, 2013).

The Bartlett test of sphericity is an indicator of the strength of the relationship among variables and an indicator of the suitability of the data towards a multivariate statistical technique, such as factor analysis (Ellis, 2013). It is an indicator of the strength of the relationship among variables. This holds true when both the variables across conditions are equal and the covariance between pairs of conditions are equal. In this study, as suggested by Field (2007), the significance of the Bartlett's test of sphericity and its associated probability was less than 0.05 . This means that values of 0.05 and below were regarded to be significant and that it can thus be concluded that the relationship among variables is strong. As such, it shows that the data were suitable to be subjected to multivariate statistical analysis, such as a factor analysis. In total, seven factors were identified after rotating the component matrix with a Normalised Varimax rotation (orthogonal rotation) as shown in Table 2.

Table 2. Factor Labels And Contextualisation

\begin{tabular}{lll}
\hline Factors & \multicolumn{1}{c}{ Factor Label } & \multicolumn{1}{c}{ Context: Factor Refers To } \\
\hline F1 & Leadership Practice & Empowerment, Encouragement And Inspirational Issues \\
F2 & Work-Related Stressors & Work Conditions Related To Teaching And Learning Process \\
F3 & Bureaucratic Influences & Destructive And Negative Management Style \\
F4 & Organisational/Planning Approach & Effective And Transparent Leadership Are Stressed \\
F5 & Managerial Relationships & Evaluation Of Supervisory Capacities \\
F6 & Workplace Culture & Pro-Active Management With Emphasis On Values And Ethical Practices \\
F7 & Distributive Leadership & Democratic Management Processes Are Applied \\
\hline
\end{tabular}

The reliability of the analysis was determined with the Cronbach Alpha Coefficients technique after identifying the factors from the data (Field, 2007). It was established that the majority of the Cronbach Alpha coefficients in this study were greater than 0.90 , which was regarded to be an excellent level of reliability and internal consistency (Field, 2007).

The correlations between the different factors were calculated using the Pearson Correlation Coefficient to specify the relationship between the variables. It was established that all factors were significantly correlated, with factor 1 at the 0.01 level and that there were also significant correlations between the other factors.

\section{FINDINGS AND DISCUSSION}

The three main strands of leadership and management theories that were discussed in this article all have value and practical applicability in the field. The different perspectives are not mutually exclusive, as if only particular theories or insights relate to a certain time or, to a greater or lesser extent, in diverse situations. Linking the degree to which 
teachers experience and are involved in the management of stress with the application of particular theories is a complicated issue and it is likely that only partial insight and understanding of problems will always be obtained. In South Africa, authors support the view that the initial emphasis that was placed on managerial theories has been complemented with a move towards democratic or participative theories (Williams, 2011; Christie, 2010). In practice, teachers who participated in the study maintained an ambivalent view. On the one hand, they showed strong support for the transformational theory in terms of which changes are led by values, beliefs and organisational goals. They believed that the existence of a compelling vision would not only assist to inspire them but could also serve as a mechanism to alleviate their stress levels. On the other hand, they realised that their supervisors played an important role in addressing problems that might have caused stress. In dealing with day-today organisational and planning issues, managerial leadership was thus perceived as the norm in schools. Teachers indicated that the only way to achieve an effective school was to ensure that, in these matters, proper emphasis should be placed on the importance of policies and procedures and other documents received from the Department of Education.

As explained above in the section on conceptual and theoretical framework, distributed leadership describes the ways that leadership activities are stretched across different people and positions within the school. By implication, teachers are seen as keen and willing participants in a variety of school-wide management activities. In this investigation, however, they indicated that there were already a whole range of stressors that influenced their professional working life and that they would not like to be involved in too many additional managerial activities. They indicated that learners' "behaviour and attitude", coupled with teaching and learning in the classroom, was already a huge responsibility. Their involvement in managerial activities should therefore be limited to the school's instructional programme. As direct custodians of the curriculum implementation process, teachers see themselves as the ones who understand instructional-related work processes better than management staff. In their opinion, teachers' involvement in teaching and learning matters would lead to better decisions and improved academic performance. When distributed leadership is accepted and implemented in teaching situations, classroom management is a closely-related concern. Teachers understood that they could not accept responsibility for the teaching and learning process without managing and organising their classrooms in a responsible and systematic way. Their primary management responsibilities were thus pegged at the level of the classroom, though very closely linked to improved school outcomes. Teachers believed that if this situation is consistently applied, a number of their current stressors would be reduced.

Teachers also tended to relate some of the stress that they experienced with the perceived performance or incompetence of school principals and the management team. Principals were still seen as managers who should apply and demonstrate hands-on management skills such as negotiation, conflict solution and stress management. Principals and management teams have to show an understanding for realities in the school situation and must be instrumental in setting up and implementing new strategies. There was a strong feeling amongst participants that the only way that the principal and management team could contribute to an effective school was to ensure that teaching and learning were always regarded as the main priorities. Different working teams in the school should also be connected in an organisational structure and be encouraged to work together to enhance school effectiveness.

The significance of empowerment is closely linked to the functioning of teams, as discussed in the previous paragraph. Empowerment can only be successful if it is led by a principal and management team that are serious about development and empowerment.

It is further recognised that there is a wide range of professional and personal development opportunities available to teachers but that these opportunities are normally only used by a small number of teachers. Another aspect of empowerment has to do with the availability of information. It seems as if information from the Department of Education about key issues is made available at schools on a regular and consistent basis and that teachers realise that they have to seize whatever opportunities are available to empower themselves.

\section{RECOMMENDATIONS}

The following recommendations are made about the involvement of teachers and staff in school management. All these aspects impact on stress and the management of stress in schools. 


\section{Teachers' Involvement}

- Teachers should only be involved in management activities that they experience as meaningful and significant.

- Participation in management must be well planned, communicated and organised.

- It is crucial for teachers to participate in curriculum planning and implementation activities.

- Classroom and instructional management is the primary management area in which teachers should be involved.

- Learners' discipline must be an integrated aspect of school management and all its facets.

\section{Involvement of The Management Team}

- The management team has to provide both traditional management and participative leadership.

- The main functions of the management team have to do with providing a vision, leading change, achievement of school goals and implementing new strategies.

- Understanding stressors and stress management are crucial roles that the management team should play.

- The management team has to realise that it has to provide leadership and emphasise the development of those who participate in the process.

- Empowerment can only be successfully filtered down through the school system if it is valued as important by the management team.

\section{CONCLUSION}

The well-documented paradigm shift from managerial leadership to transformational and distributive leadership in leadership theories could not be confirmed in this study. Although there are many examples of how aspects of the different theories are applied in practice, the reality is that managerial leadership still features strongly in schools and that, in many instances, transformational and distributed leadership is not seen as a way to manage stress in schools.

\section{AUTHOR BIOGRAPHY}

Professor C. van Wyk, Extraordinary Professor in the School for Educational Leadership Development, NorthWest University. E-mail: vanwyk.christo1@gmail.com. (Corresponding author)

Mrs. A. M. Pelser, Lecturer in the School for Educational Leadership Development, North-West University. Email: anna.pelser@nwu.ac.za.

\section{REFERENCES}

Bass, M., \& Avolio, B. J. (1991). Transformational Leadership Development: Manual for the Multifactor Leadership Questionnaire. Consulting Psychological Press: Palo Alto.

Bass, B. M., \& Avolio, B. J. (1993). Improving Organizational Effectiveness through Transformational Leadership. Sage: Thousand Oaks.

Botha, R. J. (2006). Leadership in School-based Management: a Case Study in Selected Schools, South African Journal of Education, 26(3):341-353.

Botha, R. J. (2011). Contextual Factors in the Assessment of the Effect of School-based Management on School Effectiveness, Journal of Social Sciences, 27(1): 15-23.

Bush, T. (1986). Theories of Educational Management. Harper \& Row: London.

Bush, T. (2007). Educational Leadership and Management: Theory, Policy and Practice. South African Journal of Education, 27(3):391-406.

Bush, T. (2008). Leadership and Management Development in Education. Sage: London.

Caldwell, B. J., \& Spinks, J. M. (2006). Principal matters: Excellence in Leadership: demands on professional school principals. $\{$ Web $\}$ http://www. vassp. org.au/webpages/Principal Matters/Principal Matters-Winter-2009. pdf Date of access: 25 September 2013. 
Cartwright, S, \& Cooper, C. L. (2002). ASSET An Organisational Stress Screening Tool - The Management guide. Manchester, UK: RCL Ltd.

Christie, P. (2010). Landscapes of Leadership in South African Schools: Mapping the Changes, Educational Management Administration \& Leadership, 38(6): 694-711.

Crawford, M. (2012). Solo and distributed leadership, Educational Management Administration \& Leadership, 40(5): 610-620.

Dambe, M., \& Moorad, F. (2008). From Power to Empowerment: A Paradigm Shift in Leadership, South African Journal of Higher Education, 22(3): 575-587.

Dantley, M. E. (2005). Moral Leadership: Shifting the Management Paradigm. (In English, F. ed. The Sage Handbook of Educational Leadership. London: Sage p34-96).

Davies, E. H. (2012). A Policy Perspective on the Funding of Education. (In Van Rooyen, J. ed. Financial Management in Education in South Africa. Van Schaik: Pretoria. p52-88).

Ellis, S. (2013). Statistical Consultation Services. Department of Statistics. North-West University: Potchefstroom.

Field, A. (2007). Discovering statistics. Using SPSS. 2nd ed. London: Sage Publications. North-West University: Potchefstroom.

Fink, D. (2011). Pipelines, Pools and Reservoirs: Building Leadership Capacity for Sustained Improvement, Journal of Educational Administration, 49(6): 670-684.

Flessa, J. (2009). Educational Micro politics and Distributed Leadership, Peabody Journal of Education, 84: 331-349.

Gill, R. (2003). Change management—or change leadership? Journal of Change Management, 3(4): 307-318.

Harris, A. (2004). Distributed Leadership and School Improvement: Leading or Misleading? Educational Management Administration \& Leadership, 32(1): 11-24.

Hartley, D. (2010). Paradigms: How Far Does Research in Distributed Leadership ‘Stretch'? Educational Management Administration \& Leadership, 38(3) 271-285.

Heystek, J. (2007). Reflecting on Principals as Managers or Moulded Leaders in a Managerialistic School System, South African Journal of Education, 27(3): 491-505.

Heystek, J. (2011). South African Schools: Under Pressure to Enhance Democratization and Improve Quality, Educational Management Administration \& Leadership, 39(4): 455-468.

Jackson, L. T. B. (2004). An adapted model of burnout for teachers in South Africa. Potchefstroom: NWU. (Thesis-PhD).

Leithwood, K., Jantzi, D., \& Steinbach, R. (1999). Changing Leadership for Changing Times. Buckingham: Open University Press.

Leithwood, K., \& Sun, J. (2012). The Nature and Effects of Transformational School Leadership: A Meta-Analytic Review of Unpublished Research, Educational Administration Quarterly, 48(3) 387-423.

Mannheim, B., \& Halamish, H. (2008). Transformational Leadership as related to Team Outcomes and Contextual Moderation, Israel Leadership \& Organization Development Journal, 29 (7):617-630.

Marishane, R. N., \& Botha, R. J. (2012). School Leadership in a Changing Context: A case for School-based management. Pretoria: Van Schaik.

Mncube, V. (2009). The Perceptions of Parents of their Role in the Democratic Governance of Schools in South Africa: Are they on board? South African Journal of Education, 29(1); 83-100.

Mokoena, S. (2012). Effective participative management: Does it affect Trust levels of stakeholders in schools? Journal of Social Sciences, 30(1): 45-53.

Moloi, K. (2007). An overview of education management in South Africa, South African Journal of Education, 27(3):463-476.

Naidoo, K. (2011). Stress management and its impact on work performance of educators in public schools in KwaZulu-Natal. Potchefstroom: NWU. (Thesis-PhD).

Naidoo, K., Botha, C. J., \& Bisschoff, C. A. (2011). Causes of Stress in Public Schools and its Impact on Work Performance of Educators, Journal of Social Sciences, 34(2): 177-190.

Naidoo, K., \& Botha, C. J. (2012). Management and leadership in secondary schools in South Africa, African Journal of Business Management, 6(32): 9218-9227.

Naidu, A., Joubert, R., Mestry, R., \& Mosoge, J. (2011). Education Management and Leadership. Oxford: Cape Town.

Niemann, R., \& Kotze, T. (2006). The Relationship between Leadership Practices and Organisational Culture: an Education Management perspective, South African Journal of Education, 26(4):609-624.

Ogawa, R. T. (2005). Leadership as Social construct: The Expression of Human Agency within Organizational Constraint. (In English, F. ed. The Sage Handbook of Educational Leadership. London: Sage p103-111).

Prew, M. (2007). Successful Principals: why some Principals succeed and others struggle when faced with Innovation and Transformation, South African Journal of Education, 27(3) 447-462.

Republic of South Africa (RSA).(1996). South African Schools Act, No. 84 of 1996. Government Gazette, 377(17579):1-42.

Schulze, S., \& Steyn, T. (2007). Stressors in the professional lives of South African secondary school educators, South African Journal of Education, 27:691-707.

Singh, P., \& Lokotsch, K. (2005). Effects of Transformational Leadership on Human Resource Management in Primary schools, South African Journal of Education, 25(4):279-286.

Somech, A. (2010). Participative Decision Making in Schools: A Mediating-Moderating Analytical Framework for Understanding School and Teacher Outcomes, Educational Administration Quarterly, 46(2):174-209. 
Spss Inc. (2009). SPSS 17.0 for Windows. Chicago, IL. [Web:] http://spss.com/software/statistics. Date of access: 10 November 2013.

Steyn, G. M. (2011). Continuing professional development in South African Schools: Staff Perceptions and the role of Principals, Journal of Social Sciences, 28 (1): 43-53.

Van der Mescht, H., \& Tyala, Z. (2008). School Principals' perceptions of Team Management: a Multiple case-study of Secondary schools, South African Journal of Education, 28:221-239.

Van der Vyver, C. (2012). ONWB 625-Slideshow. Potchefstroom: NWU.

Van Niekerk, E.J., \& Van Niekerk, P. du P. (2006). Strategic management in South African Education: The Leadership Dimension, Africa Education Review, 3(1+2):84-99.

Van Wyk, D. (2004). Burnout of Secondary school teachers in the Goldfield Region of the Free State Province. Potchefstroom: NWU. (Thesis-M Com).

Van Wyk, N. (2004). School Governing Bodies: the experiences of South African educators, South African Journal of Education, 24(1):49-54.

Wadesango, N. (2011). Strategies of Teacher Participation in Decision-making in Schools: a Case study of Gweru District Secondary schools in Zimbabwe, Journal of Social Sciences, 27(2):85-94.

Williams, C. G. (2011). Distributed leadership in South African schools: possibilities and constraints, South African Journal of Education, 31(2):190-200. 


\section{NOTES}

